\title{
Influencia cultural del K-pop en jóvenes limeños
}

\section{RESUMEN}

El K-pop influye culturalmente en un sector de jóvenes limeños. Este género musical llegó hace diez años a nuestro país y es parte de la denominada «ola coreana» o hallyu, movimiento cultural coreano que surgió a finales del siglo veinte y que se expande actualmente por todo el mundo.

A través de un trabajo etnográfico, la aplicación de técnicas de investigación cualitativa y cuantitativa, para lo cual se tomó una muestra de 384 personas, se ha podido comprobar que existen valores positivos que se transmiten a través del K-pop, y que los Idols, es decir, los artistas coreanos que difunden esta música, son considerados individuos de referencia y ejemplo a seguir por sus fans. No obstante, a pesar de la influencia cultural coreana que reciben del K-pop, estos jóvenes fans limeños a los cuales se les puede llamar también K-popers, no cambiarían su cultura peruana, sino más bien buscan forjar su identidad con valores positivos que puedan adquirir de otra cultura, en este caso, de la coreana.

PALABRA CLAVE: K-pop, hallyu, influencia cultural, jóvenes limeños.

\section{Cultural Influence from K-Pop in Lima's young people}

\begin{abstract}
K-pop culturally influences a sector of young people from Lima. This musical genre came more than ten years ago to our country and is part of the so-called «Korean Wave» or Hallyu, a Korean cultural movement that emerged in the late twentieth century and is now expanding worldwide.

Through an ethnographic work and the application of qualitative and quantitative research techniques, for which a sample of 384 people was taken, it has been verified that there are positive values that are transmitted through K-pop and that Idols, that is to say, the Korean artists that spread this music, are considered individuals of reference and example to follow by their fans. However, despite the Korean cultural influence they receive from K-pop, these young Lima fans, who can also be called K-popers, would not change their Peruvian culture, but rather seek to forge their identity with positive values that they can acquire from another culture, in this case, from the Korean.
\end{abstract}

KEYWORDS: K-pop, Hallyu, cultural influence, young people from Lima. 


\section{Introducción}

${ }_{\mathrm{m}}^{\mathrm{c}} \mathrm{d}_{\mathrm{j}}^{\mathrm{s}}$ ste artículo pretende explicar la influencia cultural del K-pop en un sector de jóvenes limeños. Este género musical, que es una mezcla de hip hop, música electrónica, $R \& B$ (jazz, gospel, soul y blues), pop y rock, llegó al Perú hace más de 10 años, aproximadamente, como producto de la «ola coreana» o hallyu que Corea del Sur viene expandiendo desde finales del siglo pasado en China, Japón, Medio Oriente, Estados Unidos, Latinoamérica y en parte de Europa.

El término hallyu se originó en China en el año 1999. Fue el nombre que encontraron los periodistas chinos para referirse a la gran popularidad que ganaban los artistas y las transmisiones surcoreanas en ese país (Faiola, 2006). En ese contexto, cabe señalar que por las características y formas que se han utilizado para expandir el K-pop por todo el mundo, este puede considerarse como una consecuencia del proceso de «mundialización» (Giddens, 1990).

Actualmente, los jóvenes limeños viven en un mundo globalizado y cada vez más interconectado, facilitándoles el intercambio de información con personas de otros países a través de las tecnologías de la comunicación, como internet. De esta manera, hallyu traspasa las fronteras físicas, llevando consigo el K-pop, el cual no solo presenta un estilo musical diferente, sino también una cultura distinta a la nuestra en sus tradiciones, valores, costumbres y estilos de vida.

Hallyu es resultado de la posmodernidad y los nuevos tiempos. Corea del Sur expande su cultura por medio de la música, películas y novelas (doramas), utilizando herramientas de alcance global como las redes sociales. De esta manera, los coreanos logran que ciudadanos de diversas partes del mundo conozcan sus productos culturales, los viralicen e interactúen con ellos en tiempo real. Este proceso se enmarca en lo que Castells (2009) denomina la «sociedad red».

Para Castells, los protocolos de comunicación entre diferentes culturas son la piedra angular de la "sociedad red», ya que sin ellos no existe tal sociedad, sino solo redes dominantes y comunas de resistencia. La cultura de la «sociedad red» es desarrollada sobre la base de una creencia común en el poder de las redes y de la sinergia obtenida al dar y recibir de los demás. En ese contexto, surge un paradigma tecnológico denominado «informacionalismo».
El «informacionalismo» está sustituyendo al industrialismo y consiste en el aumento de la capacidad humana para procesar la información y la comunicación humana. Esto es posible por la revolución de la microelectrónica, el software, la informática y las telecomunicaciones, todas ellas componentes de lo que puede denominarse en conjunto «sistema sociotecnológico integrado». Resultado de ello es el desarrollo de las computadoras y la comunicación digital que unidas forman lo que denominamos Internet.

Según Choque (2010), la «sociedad en red» genera que la información y el conocimiento se conviertan en los factores productivos más importantes. Al cambiarse los modos de producción, también lo hacen todos los aspectos culturales, económicos, políticos, sociales, psicológicos, comunicacionales, entre otros.

Lipovestsky (2002) señala que en la posmodernidad el poder de la sociedad radica en el consumo, en sus prácticas culturales, en la libertad individual, en la cantidad de información, la velocidad de las comunicaciones, en la búsqueda intensa del placer, el cultivo del cuerpo, la conectividad, la incertidumbre, la movilidad internacional, la indiferencia.

En ese contexto, la adopción del K-pop en los jóvenes limeños es una manifestación de su libertad individual, la cual se puede convertir en colectiva al momento de interactuar con otros semejantes. Además, es un proceso permanente de interacción cultural a través de las redes sociales y de permanente exposición a la «sociedad red», como consecuencia de la «mundialización».

\section{Conociendo los inicios del K-pop en Lima}

Para explicar el interés de muchos jóvenes limeños por el K-pop se ha tomado en cuenta el análisis de sus actitudes. Daniel Katz (Solomon, 2008) creó la «teoría funcional de las actitudes» para explicar la manera en que estas facilitan el comportamiento social. Según este modelo pragmático, las actitudes existen porque cumplen alguna función en la gente, es decir, están determinadas por los motivos de la persona.

Katz señala que la actitud tiene tres componentes: afecto, comportamiento y cognición. El afecto se refiere a lo que un consumidor siente por un objeto de actitud. El comportamiento implica las intenciones de un individuo para hacer algo relacionado con el objeto 


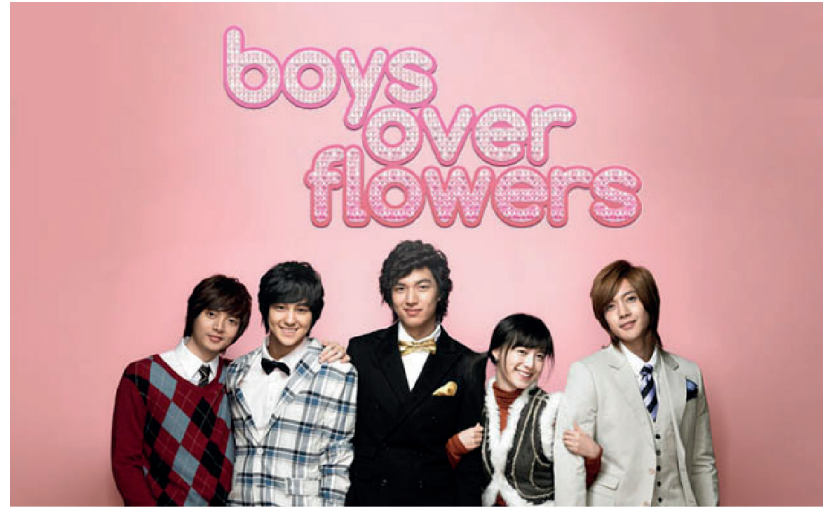

Fuente: Internet

de su actitud. La cognición se refiere a las creencias que tiene un consumidor sobre el objeto de su actitud. Estos tres componentes se conocen como el modelo $\mathrm{ABC}$ de las actitudes.

El o la K-poper, ya que este término se refiere tanto a un varón como a una mujer, desarrolla afecto por sus Idols y adopta un comportamiento que lo convierte en fans, los imita, compra souvenirs y, por el proceso de cognición, encuentra en ellos una serie de valores positivos como la fortaleza, la amabilidad, el sacrifico, entre otros, que admira y busca adoptar de manera personal.

La «ola coreana» llega al Perú en los primeros ańos del 2000. En Lima, los jóvenes de aquellos tiempos, principalmente damas, comentaban que en la programación de canales como TV Perú y Panamericana TV, ambas de señal abierta, se incluían novelas coreanas (doramas), las cuales no eran muy conocidas, sin embargo, presentaban un formato interesante y diferente a las novelas convencionales, sobre todo, porque no era común ver producciones asiáticas en nuestro país.

Según Orue (2015), novelas como «Escalera al cielo», «Todo sobre Eva», "Un deseo a las estrellas» u «Otoño en mi corazón» se comienzan a ver en la capital y se pueden considerar como el primer acercamiento de los jóvenes limeños al K-pop, el cual comenzó a ser más notorio con la emisión del drama «Boys Over Flowers», siendo uno de los actores, Kim Hyun Joong, cantante y líder del grupo SS501. De esta manera, el citado género musical comienza a ganar terreno en nuestro país.

Según Vidal (2009), al contener los «doramas» canciones de K-pop, en su mayoría baladas, o cuando es protagonizada por ídolos del género, estas se convierten en el "Caballo de Troya» del pop coreano.

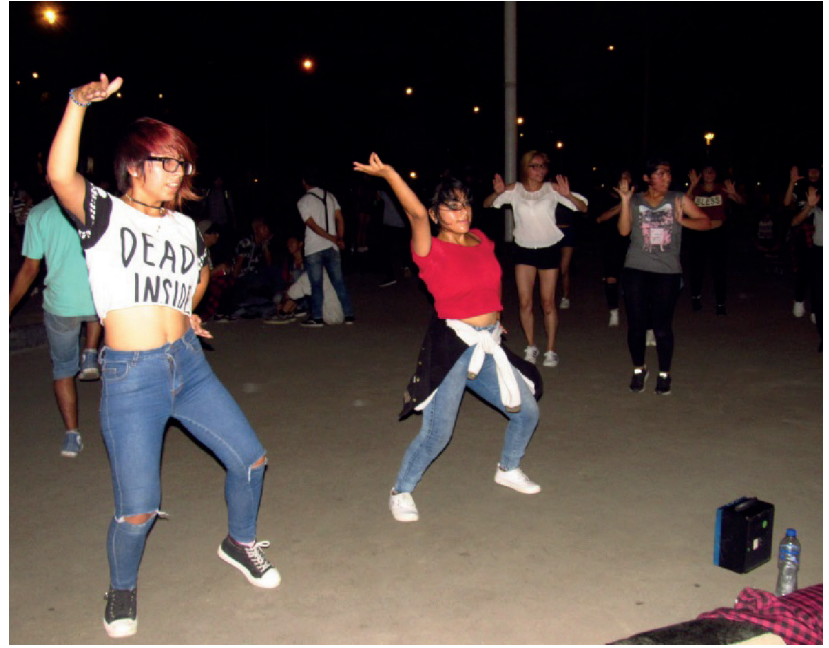

Fuente propia: K-popers en Campo de Marte

Las sentidas y desgarradoras melodías conmovían a las jóvenes y conmueven a la fecha a las nuevas seguidoras, las cuales, a pesar de no entender la letra, pueden relacionarlas fácilmente con las difíciles situaciones de los protagonistas de la historia, creando un vínculo emocional.

Como se mencionó anteriormente, a los seguidores del K-pop se les denomina K-popers, ya sean varones o mujeres. ¿Un K-poper es un fan? Para los jóvenes seguidores de esta corriente musical ambos términos serían sinónimos, no obstante, para un importante grupo de ellos la palabra K-poper es más profunda, ya que conlleva no solamente el gusto por un tipo de música en específico, sino se convierte en un estilo de vida.

\section{Sobre los K-popers}

El K-pop se ha posicionado en Lima. Todos los sábados y domingos, el Campo de Marte (antes el Parque Castilla de Lince) se convierte en una especie de anexo de Corea del Sur. Esto se debe a que cientos de jóvenes limeńos de diversos distritos de la «ciudad de los Reyes», que se califican así mismos como fanáticos del pop coreano, se reúnen en grupos de varones, mujeres o mixtos, conformados por 5 a 15 integrantes, aproximadamente, para realizar coreografías y escuchar su música favorita, en un idioma que es considerado uno de los más difíciles de aprender.

Las canciones de BTS, Exo, Big Bang, 2NE1 Super Junior, Girls Generation, Shinee, entre otros, se pueden escuchar desde equipos portátiles, conectados a sus 
teléfonos móviles o USB. La música se acompaña al compás de zigzagueantes movimientos que buscan la armonía y sincronización perfecta entre todos los integrantes, porque eso es lo que buscan, la perfección, porque los Idols lo son y ellos quieren imitarlos de la mejor manera posible.

Otro punto de reunión de los K-popers es el Centro Comercial Arenales, donde suelen reunirse para adquirir algunos souvenirs de sus Idols favoritos en tiendas como Kasoo o disfrutar de comida coreana en el restaurante $\mathrm{Yin} \mathrm{Su}$. El gusto de estos jóvenes por el K-pop, disfrutarlo con amigos, imitar a los Idols, suele estar acompañada por la curiosidad de conocer con más detalle la cultura coreana, lo cual no significa necesariamente la pérdida de la identidad cultural, sino es rescatar aspectos positivos de otra cultura que contribuya a la formación personal de los K-popers.

A los K-popers les atrae la música y lo visual (coreografías, vestimenta y el estado físico del Idol). En la cultura coreana lo físico es muy valorado y es un símbolo de progreso. En ese contexto, aplicando la teoría de grupo de referencia de Merton (1968) se podría considerar a los Idols individuos de referencia. La persona que se identifica con un individuo de referencia tratará de aproximarse a la conducta y valores de aquel individuo en sus diferentes papeles sociales. La teoría de grupo de referencia explica el comportamiento del individuo en lo que se refiere a su actitud. Para Rockeach (1973) la actitud tiene componentes afectivos, cognitivos y de conducta, coincidiendo con el planteamiento de Katz.

Flores (2013) presenta una visión positiva del K-pop, al presentarlo como uno de los géneros musicales que ha sido capaz de crear en el joven una consistencia sólida en cuanto a valores y la solución optimista de sus problemas; ya que posee un contenido de poca morbosidad y situaciones de adicción, a comparación del producto musical y de entretenimiento estadounidense.

Asimismo, el K-pop brinda a los jóvenes limeños la oportunidad de ampliar sus espacios socioculturales. Al respecto, según Peña (2011), el K-pop es un género musical que rompe barreras tanto culturales como sociales y ha logrado que varios jóvenes peruanos se unan y se apoyen, muchos de ellos sin siquiera conocerse. Los K-popers reciben la cultura coreana a través de K-pop y esta influye en ellos hasta llegar a convertirse en parte de su identidad.
Tomando como referencia a García Canclini (1995), esta situación que podemos denominar "contacto cultural» entre los K-popers limeños con la cultura coreana, no representa la imposición de una cultura sobre otra, sino es un proceso de interculturalidad.

\section{Sobre la influencia cultural del K-pop en jóvenes limeños}

Después del análisis previo realizado en páginas anteriores, se puede afirmar que el K-pop transmite la cultura coreana a los jóvenes limeños, convirtiéndose luego en parte de su identidad cultural.

No obstante, para comprobar dicha hipótesis, fue necesario la aplicación de la etnografía, describiendo el comportamiento de los grupos de fans que visitan con frecuencia el Campo de Marte, conversando con ellos y participando en eventos considerados los más importantes del K-pop en Lima. Asimismo, se ha utilizado la aplicación de técnicas de investigación cualitativa, como la observación y las entrevistas en profundidad, logrando identificar actitudes comunes entre los K-popers, resultados que se analizaron en función de tres componentes: afectivos, cognitivos $\mathrm{y}$ conductuales.

Según Sampieri (2010) el enfoque cualitativo de investigación utiliza la recolección de datos sin medición numérica para descubrir o afinar preguntas de investigación en el proceso de interpretación.

Se visitó el Centro Comercial Arenales, El Campo de Marte, se participó en eventos como Hola Korea 2016, que se realizó en el Parque de la Exposición en noviembre del año pasado, y el Festival Flores de Cerezos organizado por la Municipalidad Distrital de Barranco en setiembre del mismo año

A través de las entrevistas en profundidad se conoció con más detalle a los K-popers, los cuales coincidieron en mencionar una serie de valores que ellos consideran que se encuentran muy arraigados en la cultura coreana y que -en su opiniónfaltan cultivarse en la peruana, como son: respeto a los mayores, respeto a las damas, sacrificio, pasión, esfuerzo, dedicación, responsabilidad, liderazgo, unión, libertad, compromiso. Los entrevistados manifestaron que estos valores, que ellos califican de positivos pertenecen a una cultura diferente a la suya, los asimilan y convierten en parte de su identidad. 


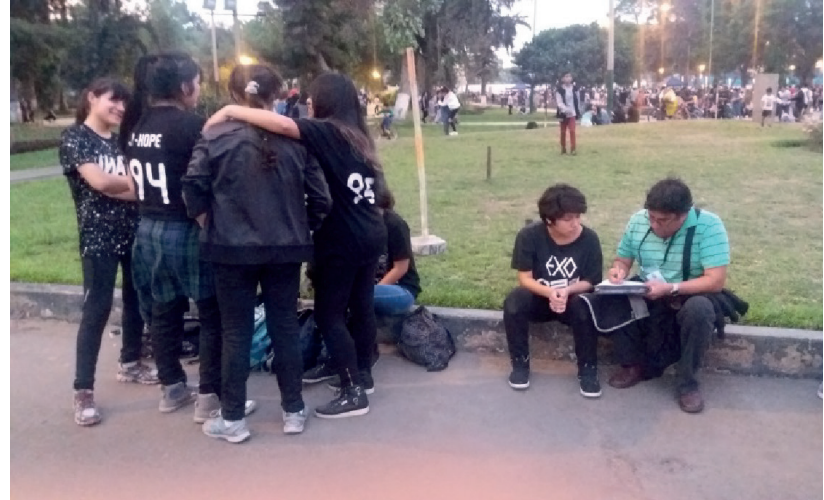

Club de fans del grupo Exo

Según Iadevito (2014) en Buenos Aires los fanáticos del K-pop no solo aprenden todo lo relacionado al género musical, sino también captan valores coreanos como el sacrificio, la disciplina, el respeto por las jerarquía, entre otros, herencias de la doctrina confuciana que se actualiza en la sociedad coreana actual y también en ciertos ámbitos y prácticas de la comunidad coreana local.

Para los K-popers, los Idols son fuente de inspiración, artistas completos que tienen una gran capacidad para interpretar diversos géneros musicales como son rock, pop y balada. Tienen habilidad para el baile y presentan shows muy visuales que son atractivos para los jóvenes. Además, y desde el punto de vista personal, son personajes con valores positivos que se deben imitar.

Si bien los K-popers son conscientes de la influencia que reciben de la cultura coreana, todos coincidieron en decir que no cambiarían su identidad peruana, ya que su afición por el K-pop es tan igual como la de cualquier otro joven limeño por el reaggeton, la salsa, el rock en inglés, la música electrónica, entre otros.

Dado que la esencia de la Antropología es el trabajo etnográfico y el análisis de contenido, resultó muy interesante llevar más allá la experiencia de conocer con más detalle a los K-popers, confirmando y extrapolando los resultados obtenidos con una encuesta, ya que era importante precisar con más detalles las motivaciones de un K-poper y la influencia cultural coreana que pueda existir en ellos.

Al respecto, se diseñó un método descriptivo de investigación, teniendo como base la teoría de Daniel Katz y el planteamiento de Rockeach sobre las actitudes. Es así que se identificó una muestra de 384 jóvenes limeños procedentes de diversos distritos de la capital. Las encuestas se aplicaron a K-popers que visitaron con frecuencia el Campo de Marte entre noviembre y diciembre del 2016.

Nuevamente, citando a Sampieri (2010), los estudios descriptivos cuantitativos buscan explicar las propiedades, las características y los perfiles de las personas, grupos, comunidades, procesos, objetos o cualquier otro fenómeno que se someta a un análisis.

\section{Resultados de la encuesta}

La edad de la mayoría de K-popers limeños (Cuadro 1) fluctúa entre los 21 y 25 años de edad (46.6\%). La mayoría de K-popers (Cuadro 2) son mujeres (70\%). No obstante, durante el trabajo de campo, se observó la presencia de muchos $\mathrm{K}$-popers varones.

El incremento del número de fans masculinos se debe al gusto por la música de estilo hip hop y las coreografías, como es el caso de Kingz, que se dedican a la realización de covers del grupo coreano Big Bang. Asimismo, otros seguidores varones suelen imitar a grupos como Exo, Super Junior, entre otros.

A los K-popers se les puede clasifcar en tres tipos de fans: se encuentran aquellos que siguen a sus grupos favoritos, escuchan su música, compran sus discos,
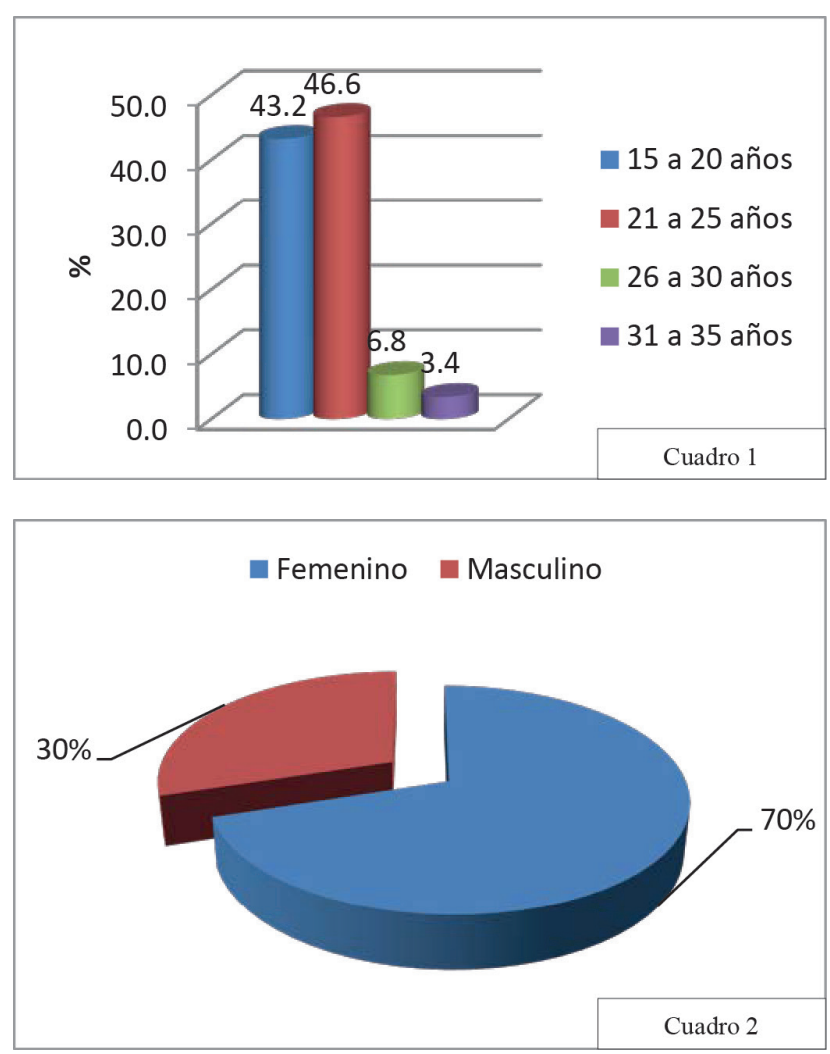
souvenirs y tienen fotos y posters de ellos. Existen otros que tienen las mismas características de los anteriores, sin embargo, son miembros activos de fansclub.

Los jóvenes limeños, principalmente mujeres, y que forman parte de estos fansclub, se dedican a publicar sobre sus actividades. También comparten fotos o información que consideran de mucho interés sobre sus Idols o grupos favoritos. Cuentan con un fanpage en Facebook y es la o el líder quien está a cargo de las publicaciones. Como una tercera categoría se puede considerar a los que dedican su tiempo a la realización de covers, es decir, la imitación musical que realizan los $\mathrm{K}$-popers de sus Idols favoritos.

Cuando un varón ingresa al mundo del K-pop y se dedica a realizar covers se preocupa más por su imagen: usa ropa de marca, el peinado de moda y se cuida físicamente, buscando un cuerpo atlético. Asimismo, suelen realizarse algunas mejoras en el rostro, como el depilado de cejas. Algunas personas pueden calificarlos de "metrosexuales», pero ellos no se consideran así, solo buscan emular a su Idol, ya que el nivel de exigencia que se requiere para representar a un artista favorito es realizar la imitación lo más exacta posible.

En el caso de las mujeres, si bien muchas de ellas prefieren a los cantantes varones, por los que sienten un amor platónico, eso no deja de lado que puedan seguir a cantantes femeninas, a quienes admiran, principalmente, por su forma de bailar y estilo en la ropa. Las Idols favoritas para las fans femeninas son 2en1, Girls Generation, T-Ara, Wonder Girls, $F(x)$, Twice, entre otras.

Al preguntar a los K-popers cuándo comenzó su gusto por el K-pop (cuadro 3), la mayoría de ellos señaló que se iniciaron durante la secundaria (56.5\%).

Respecto a la pregunta de cómo llegaron a conocer el K-pop, la mayoría de los encuestados (cuadro 4), manifestó que fue a través de los amigos (35.7\%).

Cabe señalar que la citada etapa escolar representa el inicio y desarrollo de la adolescencia, tiempo de grandes cambios, tanto físicos como de pensamiento, donde la búsqueda de la aceptación es lo más primordial.

Los amigos (Cuadro 5) son considerados la principal fuente de información sobre los Idols (40.1\%) y el mejor medio para informarse (Cuadro 6) de las actividades del K-pop en Lima (32.3\%). De ahí la necesidad de muchos K-popers de formar parte de un fansclub.

Cuando se preguntó qué significa ser un K-poper (Cuadro 7), la mayoría de ellos afirmó que es ser un apasionado del K-pop (43.2\%).

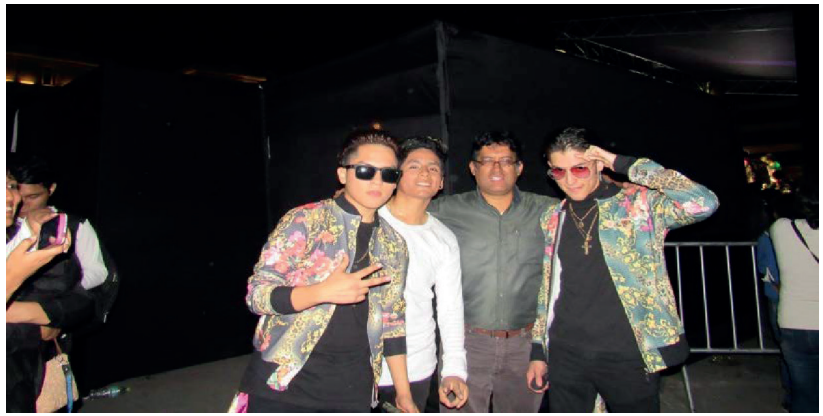

Fuente propia: Grupo Kingz, realiza covers de Big Bang
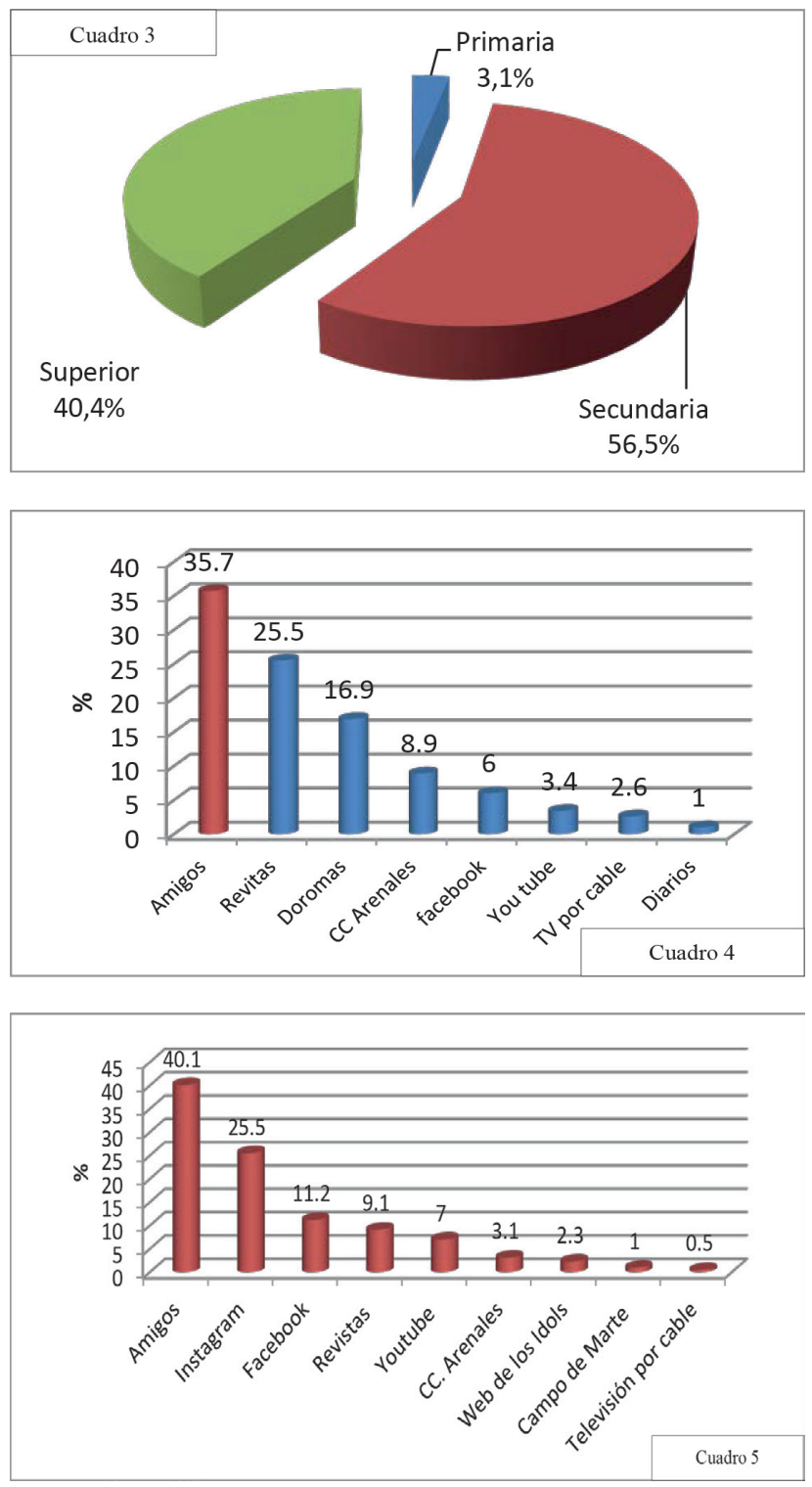

En ese contexto, al preguntar qué es lo que más les apasiona del K-pop (cuadro 8), la mayoría de los encuestados manifestó que es la música (59.9\%).

Respecto a cuál es el grupo que causa mayor apasionamiento en los K-popers (Cuadro 9), en primer 

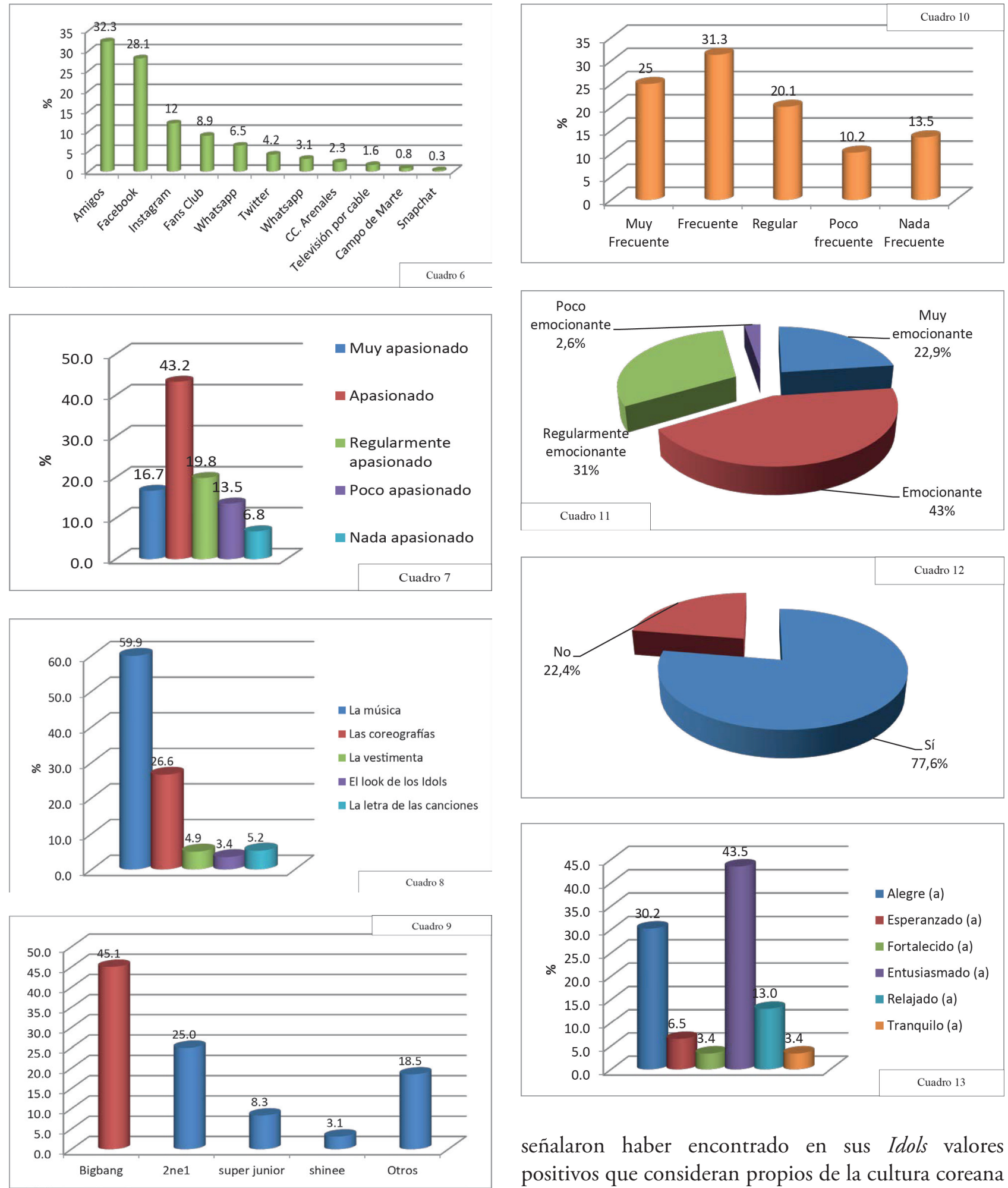

señalaron haber encontrado en sus Idols valores positivos que consideran propios de la cultura coreana y que quisieran encontrar en los peruanos, como

lugar se ubicaron a Big Bang (45.1\%), le siguen 2en1 (25\%), Super Junior (8.3\%) y Shinee (3.1\%).

Además de valorar la música, los K-popers citaron que existen otros aspectos que generan apasionamiento por el K-pop. Al respecto, las K-popers encuestadas la caballerosidad, la delicadeza, el romanticismo, la ternura, el amor, el compromiso, la fidelidad.

Tanto es el nivel de fascinación que tienen los K-poper por la cultura coreana que, el simple hecho de estar junto a un ciudadano coreano, sienten que es lo 
más cercano de estar junto a su Idol, ya que los valores que sienten por él o ella los transfiere a estas personas.

Este apasionamiento por el K-pop en jóvenes limeños y la difusión que ha alcanzado a consecuencia de ello se debe también al éxito de las redes sociales, las cuales han generado nuevas maneras de consumir la música surcoreana.

Los K-popers son usuarios permanentes de redes sociales como Facebook, Twitter, Youtube e Instagram a través de las cuales pueden escuchar y compartir sus canciones favoritas en tiempo real, así como observar las imágenes y videos de sus Idols. En este contexto, la aparición constante de nuevos grupos y cantantes, así como de nuevas producciones discográficas que se difunden por las redes sociales contribuyen a la expansión del K-pop.

Al respecto, tal como comenta Iadevito (2014), algunos de los elementos característicos y distintivos que han vuelto al K-pop sumamente atractivo $y$ atrayente en Argentina, como sucede en Lima, son los siguientes:

- Las canciones con letras positivas y pegadizas;

- El uso de la tecnología para la realización de las súper producciones en video y en vivo;

- El vasto mercado de «industrias culturales» que existen por detrás del K-Pop

Las letras de las canciones del K-pop no se enfocan en el desamor y la tristeza, sino en recuperar en los jóvenes valores tales como la responsabilidad, el compromiso, la formulación de objetivos y metas para un trabajo organizado y sostenido en el tiempo.

Respecto a la búsqueda de información sobre el K-pop y sus Idols (Cuadro 10), los K-popers señalaron que es «frecuente» $(31.3 \%)$.

Cabe recordar, según el Cuadro 6, que el Facebook es considerado el segundo medio más importante para conocer sobre las actividades de K-pop en Lima (28.1\%), pues el primer lugar lo ocupan los amigos. No obstante, el Facebook podría compartir esa posición junto a los amigos, ya que la mayoría de los K-popers se comunican a través del Facebook Messenger, que es el sistema de chat de la citada red social.

Tal como se comentó anteriormente, el afecto es una de las variables que influye en la actitud de los K-popers, generando en ellos situaciones emocionales que afectan su motivación. En ese contexto, utilizando la Escala de Likert para identificar su nivel de emoción por el K-pop, la mayoría de los encuestados (Cuadro
11) lo calificó de emocionante (43.5\%), y que este género musical (Cuadro 12) ha generado un cambio emocional importante en su vida (77.6\%).

En ese contexto, cuando se les preguntó sobre qué sienten al escuchar K-pop (Cuadro 13), la mayoría de K-popers manifestó sentirse entusiasmado $(43.5 \%)$ y en segundo lugar sentir alegría (30.2\%).

Asimismo, al preguntar a los K-popers que sentimiento despierta en ellos el K-pop (Cuadro 14), la mayoría de encuestados manifestó que es Libertad (49\%) y en segundo lugar admiración (17.4\%).

Para la mayoría de K-popers, el K-pop (Cuadro $15)$ es importante en su vida $(73.2 \%)$, sintiendo el $79.4 \%$ de ellos que afecta «muchas veces» su estado de ánimo (Cuadro 16).

Con relación a qué aspectos son los que valoran los $\mathrm{K}$-popers de sus Idols (Cuadro 17), mencionaron que es el ritmo (33.6\%), el estilo (26.6\%) y la creatividad $(16.4 \%)$

Respecto al nivel de identificación de los K-popers con las letras de las canciones del K-pop (Cuadro 18), la mayoría de K-popers afirmó sentirse identificado con las canciones $(62.2 \%)$, ya que transmiten la forma de pensar y sentir de su Idol favorito.

En ese contexto, dado el alto nivel de influencia de los Idols, la mayoría de K-popers sostuvo que el K-pop (Cuadro 19) afecta su forma de ser y conducta $(65.1 \%)$.

Finalmente, al preguntar a los K-popers sobre la posibilidad de que el K-pop haya afectado su identidad cultural (Cuadro 20), la mayoría de ellos (55.5\%) manifestó que no afectó y que están orgullosos de ser peruanos. Al respecto, cabe señalar lo mencionado por Giddens (1990), que el proceso de mundialización de la cultura no implica necesariamente la homogeneización de los gustos y de los hábitos culturales, como si todo el planeta viviese una realidad unidimensional.

\section{Conclusiones}

Tal como se refleja en los resultados, existe influencia cultural del K-pop en los jóvenes fans limeños, sin embargo, la mayoría de estos no cambiaría su cultura, al señalar que se sienten orgullosos de ser peruanos y que la fascinación por el K-pop es tan igual como cualquier joven podría sentirlo por el reggaeton, la salsa o el rock en inglés, sin que ello signifique la pérdida de su identidad. 

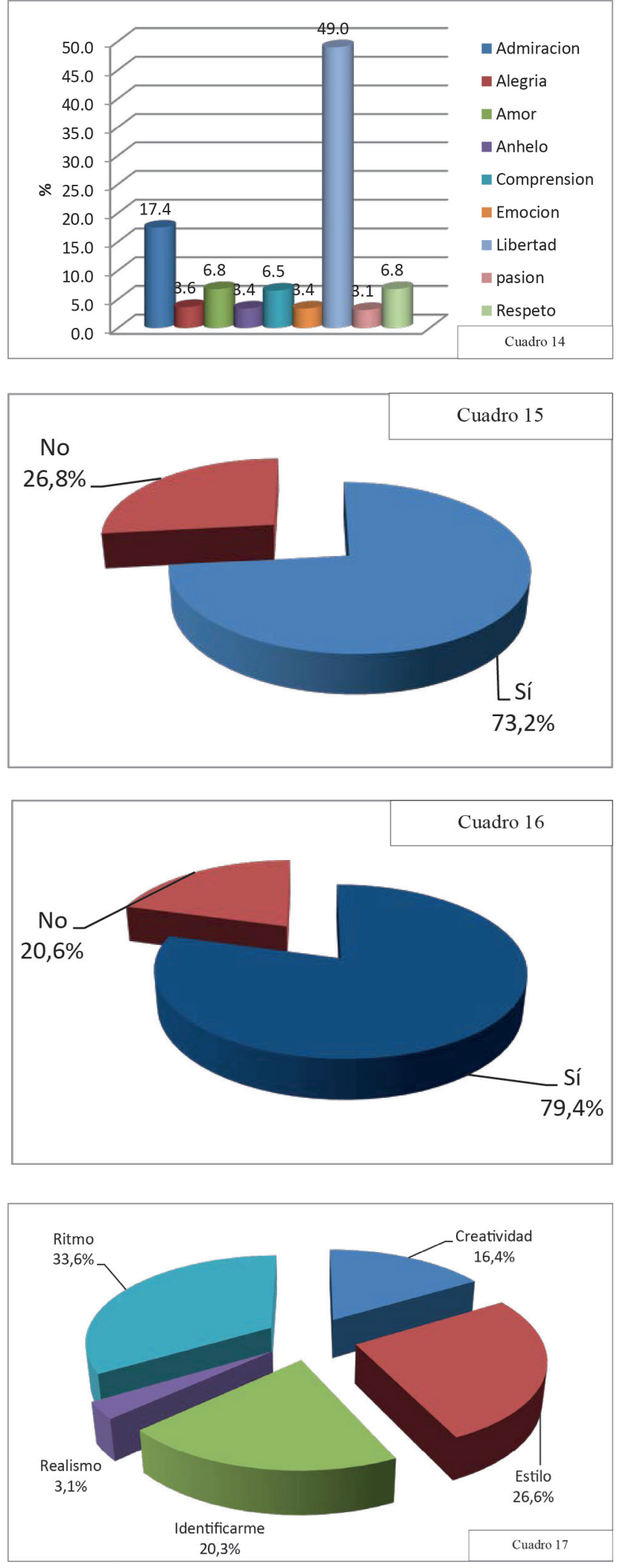
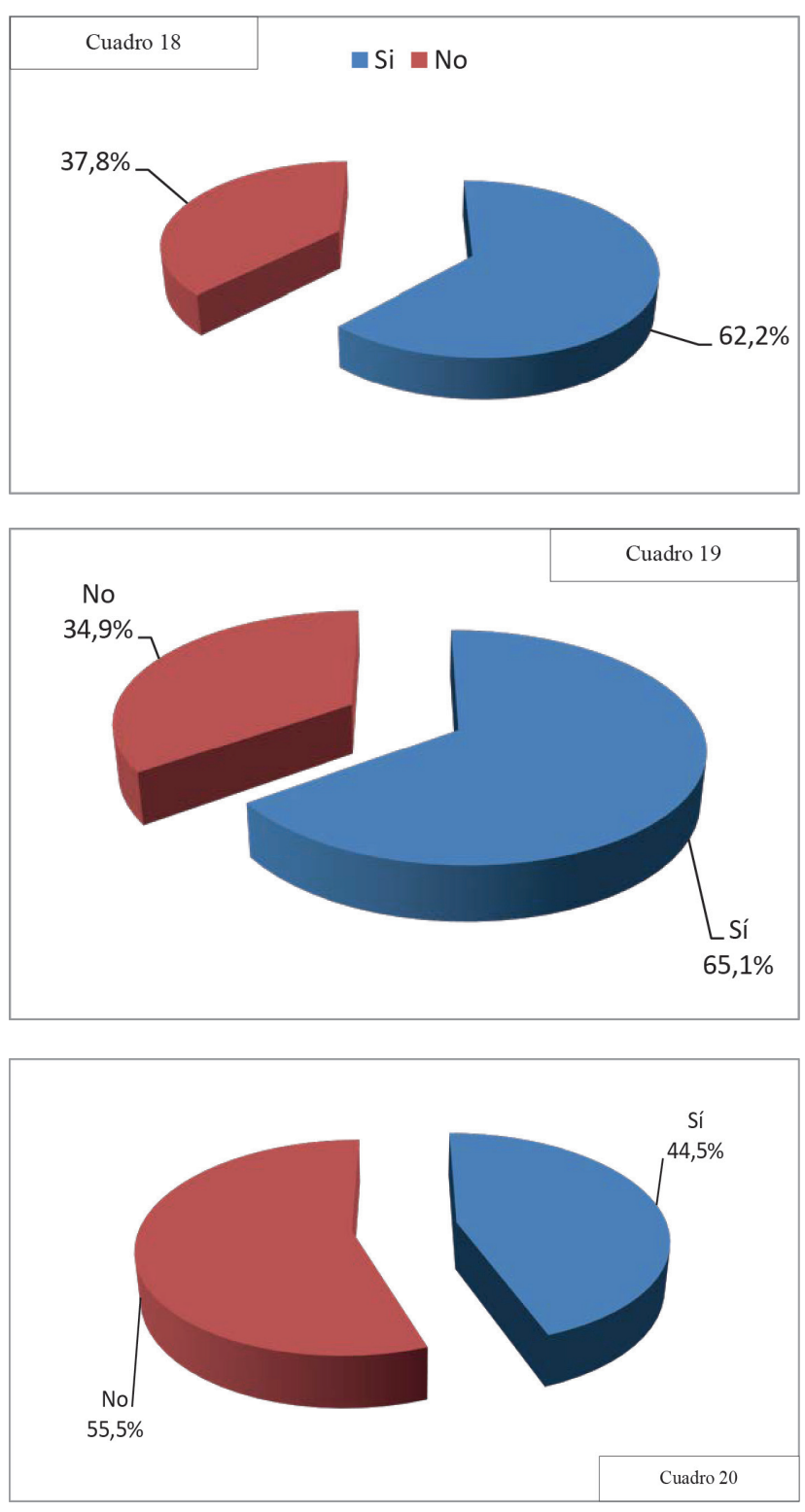

Como estilo musical, el K-pop fomenta a través de su música y sus Idols valores positivos en jóvenes varones y mujeres limeños, como son el respeto a los mayores, respeto a las damas, sacrificio, pasión, esfuerzo, dedicación, responsabilidad, liderazgo, alegría, unión, libertad y compromiso, los cuales consideran que se han perdido en la sociedad peruana.

Los Idols son considerados por los fans o K-popers como individuos de referencia, ya que son fuente de inspiración, artistas completos que tienen una gran capacidad para interpretar diversos géneros musicales como son rock, pop y balada, así como la habilidad para el baile y el desarrollo de shows muy visuales que son atractivos para los jóvenes. Los fans del K-pop valoran en los Idols su ritmo, estilo y creatividad. 


\section{Bibliografía}

Castells, M. (2006). La sociedad red: una visión global. Madrid: Alianza Editorial.

Castells, M. (2009). Comunicación y poder. Madrid: Alianza Editorial.

Choque, R. (2011). Nuevas competencias tecnológicas en información y comunicación. Lima: Concytec.

Faiola, A. (2006). Japanese Women Catch the "Korean Wave». Washington: Washington Post Foreign Service.

García Canclini, N. (1995). Consumidores y ciudadanos. México: Editorial Grijalbo.

Giddens, A. (1990). Consecuencias de la modernidad. Madrid: Alianza Editorial.

Lipovetsky, G. (2003). La era del vacío. Buenos Aires: Editorial Anagrama.

Merton, R. K. (1968). Social Theory and Social Structure. Londres: Simon and Schuster.

RoKeach, M. (1973). The Nature of Human Values (Vol. 438). New York: Free press

Solomon, M. (2008). Comportamiento del consumidor. México: Pearson Educación.

\section{Páginas web}

Flores, A. (2013). ¿K-pop, nueva opción de identidad peruana? Recuperado de: http://www.comunicacionunap.com/ index.php/rev/article/view/39/39

Iadevito, P (2013). El consumo del K-pop en Buenos Aires. Recuperado de: http://sedici.unlp.edu.ar/ handle/10915/52649

Peña, X. y otros (2011). Adolecentes fans del -pop en Lima. Recuperado de: http://comunidadkpop.wordpress.com/

Orue, P. (2015). El K-pop llegó para quedarse. Recuperado de: http://elcomercio.pe/blog/koreafighting/2015/04/ el-k-pop-llego-para-quedarse

Vidal, L. (2009). Kpop: El Hallyu Wave en el Perú desde las teorias y metodologias de Invstigación. Recuperado de: https://www.academia.edu/3462423/Kpop_ El_hallyu_Wave_en_el_Per\%C3\%BA_desde_las_ Teor\%C3\%ADas_y_Metodolog\%C3\%ADas_de_Invest igaci $\% \mathrm{C} 3 \% \mathrm{~B} 3$ n?auto=download 